\title{
A SIMPLIFIED NUMERICAL DECISION-MAKING METHODOLOGY FOR PHYSICAL ASSET MANAGEMENT DECISIONS
}

\author{
S. Burnett ${ }^{1} \&$ P.J . Vlok ${ }^{2 *}$ \\ Department of Industrial Engineering \\ University of Stellenbosch, South Africa \\ ${ }^{1}$ Sulene. burnett@daimler.com, 2pjvlok@sun.ac.za
}

\begin{abstract}
The management of physical assets has become a popular field recently, and is acknowledged in many disciplines worldwide. Physical Asset Management (PAM) is a complex subject that requires the participation of many disciplines. Maintenance management, together with accurate and effective decision-making, is vital for achieving successful PAM.
\end{abstract}

The primary objective of this research project was to identify the possibility of simplifying maintenance-related decision-making. With the focus on numerical decision-making techniques, the secondary objective was to investigate the practicality and useability of combining appropriate techniques to create an easily useable and understandable methodology to support maintenance-related decisions.

The results confirm the practicality and useability of a simplified numerical decision-making methodology. By concentrating on the core operational questions related to maintenance, and by combining the most appropriate techniques, a simplified numerical decision-making methodology can ease the decision-making process on an operational level. This can accomplish successful PAM in a proactive, preventive and simplified manner.

\section{OPSOMMING}

Die onderwerp van Fisiese Bate Bestuur (FBB) het ' $n$ gewilde navorsingsveld geraak oor die afgelope paar jaar. $F B B$ is ' $n$ komplekse onderwerp en vereis insette van verskeie dissiplines. Effektiewe bestuur van instandhouding sowel as doeltreffende besluitneming is noodsaaklik vir suksesvolle FBB.

Die primêre doel van hierdie navorsingsprojek was om die moontlikheid van vereenvoudigde besluitneming met betrekking tot instandhouding, te ondersoek. Met die fokus op numeriese besluitnemingstegnieke was die sekondêre doel om die praktiese toepassing van ' $n$ gepaste tegniek-kombinasie te ondersoek om uiteindelik ' $n$ maklike, bruikbare en verstaanbare tegniek-kombinasie te skep wat instandhouding verwante besluite kan ondersteun.

Die resultate bevestig die bruikbaarheid van ' $\mathrm{n}$ eenvoudige numeriese besluitnemings tegniek-kombinasie om die besluitnemingsproses op operasionele vlak te verlig. Deur te konsentreer op instandhouding verwante kern operasionele vrae, en deur die mees gepaste tegnieke te kombineer, kan ' $n$ vereenvoudige numeriese besluitnemingsmetodologie die besluitnemingsproses op operasionele vlak verlig. Dit kan FBB suksesvol op ' $n$ pro-aktiewe, voorkomende en vereenvoudige manier uitvoer.

\footnotetext{
${ }^{1}$ The author was enrolled for an M Eng (Industrial) degree in the Department of Industrial Engineering, Stellenbosch University.

* Corresponding author
} 


\section{$1 \quad$ INTRODUCTION}

In recent decades, all types of organisations have increasingly recognised the importance of managing physical assets. The topic of physical asset management (PAM) is evolving rapidly in various engineering disciplines worldwide.

Amadi-Echendu [1] defines a physical asset as follows:

An entity that is capable of creating, sustaining or destroying value at any stage in its life-cycle.

A physical asset can be any item that is owned for continued use, long-term or short term, to earn economic benefit for an organisation. Such assets need to be managed to yield benefit. The term 'asset management '(AM) is defined by authors such as Schneider et al. [2], Mitchell [3], and Hastings [4], to mention a few. Tywoniak et al. [5] provide consensus with the following definition:

Asset Management is the process or cycle in which assets are 'put through' in order to create a product or provide a service at optimum level.

Mitchell [3] mentions that the management of assets has been adopted by manufacturing, process, operation, and production industries. In this context, and according to Hastings [4], typical assets can include any physical items: machinery, buildings, vehicles, pipes, and wires, as well as associated information, technical control, and software systems that are used to serve a business or organisational function. From this, an engineering perspective on AM concentrates on the operational performance of physical assets.

Mitchell [6] points out the need to maintain and increase revenue, effectiveness, and customer satisfaction while reducing operating, support and capital costs. These necessities need to be balanced, and are crucial to achieving effective AM. This is considered to be the largest challenge in operation and production enterprises. This article primarily focuses on the management of tangible, physical assets.

\section{PHYSICAL ASSET MANAGEMENT (PAM)}

Many industries commonly see PAM as an equivalent of maintenance, which is not the case. PAM encompasses a broader set of activities than maintenance alone - a view supported by Myburg [7]. Maintenance is primarily concerned with keeping existing equipment in an operating condition, whereas PAM is a mixture of technical and financial aspects combined with management's decision-making. Mitchell [3] mentions the importance of balancing these aspects in order to manage physical assets effectively and efficiently to achieve successful operations.

A standard for managing physical assets was introduced by the Institute of Asset Management (IAM), which serves as a professional body for those involved in the acquisition, operation, and care of physical assets. This was done in collaboration with the British Standards Institution (BSI) and various other organisations. The Publicly Available Specification 55 (PAS 55) standard provides a holistic view of what needs to be done to manage physical assets for business objectives at any point in their life cycle. It defines PAM as follows:

Physical asset management is the systematic and coordinated activities and practices through which an organization optimally and sustainably manages its assets and asset systems, their associated performances, risks and expenditures over their life cycles for purpose of achieving its organizational strategic plan. 
Thus PAM is an aggregation of activities, focusing on the physical assets responsible for the flow of operations. According to Mitchell [6], the main objective of PAM is to increase the value and return of physical assets that generate revenue and profitability within production, manufacturing, and process industries. In striving to achieve all of this, it is necessary continually to improve operations.

Although it is still believed that PAM is equivalent to maintenance, Amadi-Echendu [1] notes that PAM is a paradigm shift away from mere maintenance. And Mobley [8] mentions that effective maintenance is one of the most important driving forces behind efficient and reliable operations. Even though many industries are armed with this knowledge, ineffective maintenance practices are still performed. This emphasises the need to optimise maintenance practices in order to obtain the maximum benefits from assets. Therefore optimised maintenance activities in the PAM environment are of great value.

\section{ROLE OF MAINTENANCE IN PAM}

Maintenance has been around forever because of the need to keep equipment operable. Historically, maintenance was only done on equipment when a failure occurred and it was no longer possible to run the equipment. This is also known as a breakdown. According to Ben-Daya et al. [9], this type of maintenance is now seen as reactive or corrective maintenance. However, over the past century, maintenance has become an acknowledged aspect in any organisation, and different maintenance strategies and sub-strategies (known as tactics) have developed over the years. There are three main kinds of maintenance strategy: life improvement maintenance, proactive maintenance, and reactive maintenance.

Life improvement maintenance involves the redesign of a system or a part in an attempt to eliminate recurring failures. It is also known as design out maintenance.

Proactive maintenance is about acting in advance to prevent or predict possible failure occurrences. It can be further divided into two different maintenance sub-strategies or tactics: preventive maintenance (PM) and predictive maintenance (PdM). PM involves the condition of an asset or the time it has been in operation. The condition, deterioration, or time of operation is monitored in order to indicate when the probability of failure increases. Thus PM is done to prevent failure occurrences. PdM involves the detection of condition, together with statistical analyses, to predict when a failure can be expected. Thus PdM maintenance is executed in accordance with the failure prediction.

Reactive maintenance is executed once a failure has occurred, as a corrective action - as described earlier with the traditional maintenance approach. This corrective response to a failure occurrence can be either immediate or deferred.

In order to achieve maintenance excellence, the planning of maintenance activities should be done correctly and effectively. Successful planning of maintenance activities is crucial to the execution of PAM. The four maintenance tactics consist of different types of maintenance that can be applied; and thus various decisions are generated when it comes to selecting the most appropriate tactic. For this reason, decision-making is a very important aspect of planning maintenance and ultimately of managing physical assets.

\section{DECISION-MAKING IN PAM}

Decision-making is a primary function of management, and so its importance should not be underestimated. Many important theorists and practitioners, such as Al-Tarawneh [10], consider decision-making to be the core managerial function. Effective decision-making is a vital task that enables an organisation to function properly. It also helps it to use all available resources to achieve its objectives. 
Rue $\&$ Bayrs [11] state that, in reality, managers must make decisions when they perform managerial functions. Such functions include planning, organising, staffing, leading, and controlling. Moreover, a manager must first be a good decision-maker in order to be a good planner, organiser, staffer, leader, and controller. Even though experienced decisionmakers expect high quality outcomes, they can be misled by their confidence and their sometimes-too-quick judgement. High quality decision-making is done within a confidence interval, and thus there is always the possibility of disappointment. In order to prevent disappointment or to increase confidence in a decision, available decision-making methods can be used.

In the area of PAM, and especially maintenance, numerous decisions need to be made daily. A few examples are: What is the optimal maintenance tactic to use? When can the next failure be expected? What is the probability of failure? How often should maintenance be done? What assets need to be maintained? Should an asset be repaired or replaced? These decisions are mostly at an operational level, and are made repeatedly. Many different techniques can be used to support decisions of this type; a few are discussed below.

- $\quad$ Criticality analysis - used to identify and prioritise critical areas or items in a system by means of linear ranking.

- $\quad$ Failure mode analysis - used to analyse and prioritise different failure modes of an item. This also uses linear ranking or decision tree analysis.

- Reliability analysis - investigates the reliability and performance of a system or item to indicate the chance of a failure occurrence, and is accomplished using statistical analysis.

- $\quad$ Failure statistics - investigate the failure behaviour of a system or item to determine the possibility of failure or estimate the residual life, through statistical analysis of historical failure data.

- $\quad$ Priority rating analysis - used to prioritise items by use or by a rating system related to criteria. This calculates importance in accordance with assigned criteria weights.

- Decision tree analysis - maps the logical flow of events graphically to find alternatives to support the decision-making process, taking into account occurrence probabilities.

- $\quad$ Alternative comparison method - compares possible solutions relative to given criteria that are related to a given problem. It also includes a type of ranking method, and calculates importance according to assigned weights.

- Pareto analysis ( $80 / 20$ rule) - identifies 80 per cent of the problems, indicating that most of the time 80 per cent of the problems are due to only 20 per cent of the causes.

There are various publications in the literature that discuss different decision-making techniques, both qualitative and quantitative. However, little or no evidence was found of applying and implementing these techniques to solve informal PAM related decisions on an operational level. Due to this lack of evidence in the literature, shortcomings with the numerical decision-making techniques were identified by means of dialogue with various practitioners. In practice, operational PAM decisions are made using discussions in meetings and by reaching agreement on circulating opinions. One downside of this is that, when considering different opinions in meetings, one participant can often easily dominate the others. A result of this is that the opinions of soft-spoken practitioners are withheld and not taken into account. During a visit to the industry, various complaints were noted about the inconsistency and inaccuracy of operational PAM decision-making, mostly in the maintenance environment. This can have major consequences, such as making inefficient decisions, that can lead to major losses in production as well as to financial losses. In clause 4.3 of PAS 55-2, various adverse effects of inefficient decision-making are mentioned, such as extensive downtime for maintenance; increased safety, health, and environmental risk to personnel; and additional cost or lost income due to poor timing of planned activities. In practice, the need for such techniques is realised more and more. 


\section{MULTI-CRITERIA DECISION-MAKING IN PAM}

The need for maintenance in PAM is highlighted, together with the importance of decisionmaking, especially on an operational level. Although various mathematical decision-making techniques are available to assist the decision-making process, these techniques are not popular because time is a limited resource and they are inherently complex. In most cases, managerial decisions are based on human judgement, discussion, and previous experiences, which is not ideal.

Current decision-making techniques that are relevant to PAM decisions are mostly designed to focus only on optimising one criterion, and they neglect others. Therefore there is a need for decision-making techniques that support multiple criteria to execute PAM-related decisions effectively.

No company wants to over- or under-maintain its facilities. In either case there will be an increased production or service cost, so it is important to find an appropriate balance. It is necessary to study methods and procedures where concerns about multiple conflicting criteria can be formally incorporated into the maintenance planning process. This is required on an operational level where people can use numerical decision-making techniques without effort and without taking up too much time. Hence, the simplification of numerical decision-making techniques is emphasised. The aim is to implement simplified techniques for PAM-related decisions on an operational level.

A simplified numerical decision-making methodology for PAM-related decisions was proposed to support the decision-making process on an operational level. The purpose of this methodology is to be quick and easy to use without requiring too much effort, and it should not confuse the decision-maker. It should provide prompt and accurate results to make the use of the methodology worthwhile. Appropriate techniques for the development of this methodology are selected and combined. However, in order to select the most appropriate techniques, frequently-used decisions are identified to create a framework for the development of the methodology.

\subsection{Decision selection}

The questions on which the decisions selected to develop the methodology are based are:

- What assets should be maintained?

- Which asset should be maintained first?

- What failure causes the need for maintenance?

- Which failures should be treated first?

- What type of maintenance should be done?

- How urgent are the required maintenance actions?

These questions are used to formulate three objectives as a guideline to develop a simplified PAM decision-making methodology:

1. Identify assets that are critical to operations and that require immediate maintenance.

2. Prioritise the failure modes of each critical asset to address these modes in order of importance or impact.

3. Select the most appropriate maintenance tactic for each failure mode.

These objectives are organised in chronological order to create three methodology phases: Identify, Prioritise, and Maintain. These phases can be followed iteratively, and thus a continuous cycle is created, as shown in Figure 1. 


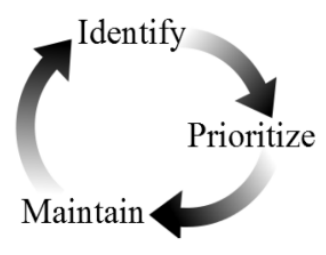

Figure 1: PAM decision-making methodology phases

The first phase, Identify, is the critical asset identification phase in which the critical assets of a system are identified. The reason for this is to highlight the critical focus point. These assets are analysed and prioritised to identify which should be addressed first and how urgent the responses should be. The second phase, Prioritise, is where the failure modes of each critical asset are further investigated and prioritised according to importance. Lastly, in the third phase, Maintain, the most appropriate maintenance tactic is selected for each failure mode. As the failure modes are maintained in the prioritised order, other assets in the system will become critical, and thus this cycle should be repeated continuously.

\subsection{Technique selection}

\subsubsection{Tactical analytical hierarchal process for prioritisation (T AHPP)}

TAHPP is derived from a process called analytical hierarchal process (AHP). The AHP approach was developed by $\operatorname{Dr}$ Thomas L. Saaty in 1980. Saaty [12] states that the development of the AHP was triggered by the lack of decision-making methodologies that are easily understood and easily implemented to enable complex decision-making. Bushan \& Rai [13] mention that the effectiveness and simplicity of this approach caused it to become rapidly and globally acknowledged in multiple disciplines. Fülöp [14] explains that an AHP is used to convert subjective data of relative importance in order to define a set of overall weights. The subjective data is obtained by comparing the attribute or alternative pairs, and determining which is more important than the other, as supported by Laininen \& Hämäläinen [15]. Consequently, only two alternatives are considered at a time, and they are compared according to the given criteria.

The criteria consist of quantitative rates with qualitative descriptions, and are shown in Table 1. Expert decision-makers are needed for this comparison because the alternatives should be understood.

Table 1: AHP rating scale adapted from Belvilaqua \& Bragliab (2000)

\begin{tabular}{lll}
\hline \hline Rate & $\begin{array}{l}\text { Qualitative } \\
\text { Scale }\end{array}$ & Description \\
\hline 1 & Equal & The two attributes contribute equally to the criteria \\
3 & $\begin{array}{l}\text { Marginally } \\
\text { strong }\end{array}$ & Experience and judgement slightly in favour of one attribute over the other \\
5 & $\begin{array}{l}\text { Strong } \\
7\end{array}$ & $\begin{array}{l}\text { Very strong } \\
\text { Experience and judgement strongly in favour of one attribute over the other } \\
\text { practice. }\end{array}$ \\
Extremely & $\begin{array}{l}\text { The evidence favouring one attribute over another is of the highest possible } \\
\text { order of affirmation }\end{array}$
\end{tabular}

The comparison values are presented in an $\mathrm{n} \times \mathrm{n}$ square matrix, with diagonal values equal to 1 . Each level of the hierarchy is compared in this manner. As mentioned, this is a top- 
down approach; therefore the highest level attributes are compared first, which are usually the top criteria. Each level is compared, down to the alternatives that are considered as possible solutions to the problem.

The nxn matrix created with the pairwise comparison is squared and normalised iteratively in order to find a steady state eigenvector. The eigenvector is also considered as the priority matrix representing the individual priorities of each alternative. If the hierarchy consists of three criteria and four alternatives, all four alternatives will have a separate priority for each criterion. These priority matrices are multiplied by another matrix, made up by the criteria weights. This result is the final decision priority value for all alternatives.

When using TAHPP, the consistency of the decision-maker is also measured to ensure that the comparisons remain consistent. Escobar et al. [16] explain the calculation of a consistency ratio (CR) relative to large samples of purely random judgement. The CR must be below 0.1 to consider the judgement to be accurate.

TAHPP is selected because it aims to quantify relative priorities for a given set of alternatives. A pairwise comparison is done on a ratio scale from 1 to 9 , and is based on the decision-maker's judgement. As explained, the consistency of the decision-maker is also measured, indicating whether or not the result can be considered accurate. It takes into account the system as a whole, and breaks it down to find a logical solution. It is especially suitable to find the best alternative with multiple criteria involved. This analysis can be applied to all the core assets of the system. It can also be applied to smaller sections, depending on the areas of assessment.

\subsubsection{Simple multi-attribute rating technique (SMART)}

SMART is a structured methodology designed to handle the trade-offs among multiple objectives, and is one of the simplest methods used for multi-criteria decision-making (MCDM).

Starfield [17] describes how, with SMART, each alternative is given a direct rating value with respect to each criterion. This rate represents how well the alternative satisfies the criterion. The rating scale would typically be between 0 and 1,0 being the worst case scenario and 1 the best. By multiplying the alternatives' rates, rij, by the criteria weights, $w i$, and summarising them, an evaluation value, $V(A j)$, is calculated according to the following equation:

$$
V\left(A_{j}\right)=\sum_{j=1}^{n} w_{i} r_{i j}
$$

This value is used to prioritise the alternatives. This is explained in the work of Barron \& Barret [18].

Because SMART is a relatively quick and easy analysis that provides meaningful outcomes, it is selected for the failure mode prioritisation phase. An asset can have a large number of different failure modes; so if an asset is identified as critical, all of the failure modes need to be assessed to obtain accurate prioritisation.

\subsubsection{Technique for order of preference by similarity to ideal solution (TOPSIS)}

TOPSIS is described by Sachdeva et al. [19] as a decision-making technique that finds a solution - one that is closest to the ideal and furthest from the negative ideal - to a multicriteria problem. The negative ideal solution is considered to be the worst option. Olson [20] states that TOPSIS only needs limited subjective input from the decision-maker, weighing alternatives against given criteria. According to Marovific [21], TOPSIS is an uncomplicated technique and is very useful for real world multi-criteria problem solving, providing the decision-maker with the best alternative. It is a quick, easy rating technique that uses matrix normalisation and multiplication to identify the one alternative closest to the ideal and furthest from the negative ideal. By using this technique, the best maintenance tactic can be selected for each failure mode. 


\subsection{A simplified numerical decision-making methodology}

The first technique, TAHPP, prioritises the critical assets by categorising the assets into one of three priority groups. The criticality of the assets is plotted on a criticality grid, graphically showing the categorisation of an A-, B-, or C-priority category. For each of these categories different strategies are used to analyse the assets' failure modes further.

A Pareto analysis is applied to the criticality of the assets to determine the urgency of the required actions. Figure 2 graphically explains the concept of the methodology.

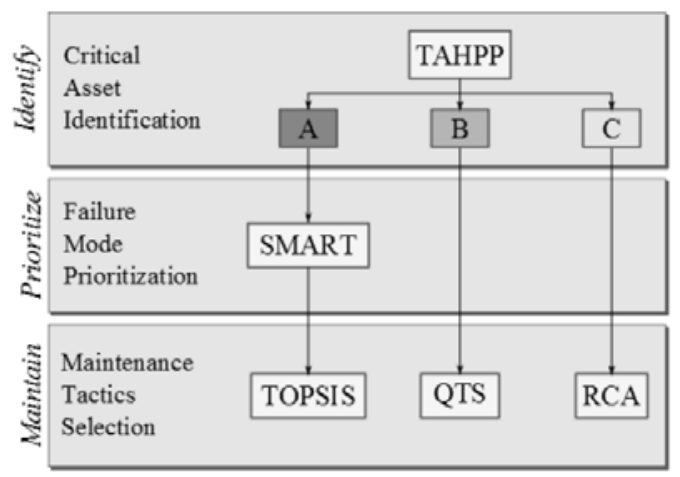

Figure 2: Methodology concept

Assets with a C-priority are labelled as non-critical, and a long-term investigation is proposed to identify the root causes of the failures. A root cause analysis (RCA) is required to find the possible root causes for the failures of these assets. A further extensive investigation is then required to resolve the problems. Assets with a B-priority are of moderate importance; for this reason it was decided to do a quick tactic selection (QTS). This serves as a temporary solution while keeping the assets in working order until the maj ority of the criticality is addressed.

The most critical assets, those with an A-priority, need immediate attention. An extensive investigation into their failure modes is required to obtain valuable results. An assessment is executed to identify and prioritise all the possible failure modes as quickly and accurately as possible. The technique selected for this is SMART. Even though the number of possible failure modes of an asset or a set of assets can become very large, SMART can be used to obtain accurate results in a relatively short time. The failure modes are also plotted on a priority grid to categorise the asset priorities visually. A Pareto analysis is also applied to determine the urgency of the actions to be executed.

To summarise: an appropriate maintenance tactic is selected for each of the failure modes using TOPSIS. Figure 3 shows the combination of the selected techniques, proposing the PAM decision-making methodology.

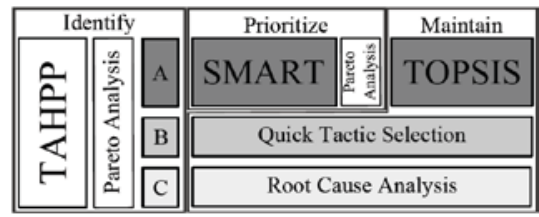

Figure 3: Methodology technique combination

The aim is to strive continually for operational excellence (OE) with the use of PAM initiatives. By focusing on the maintenance aspects, an adequate combination of best practice techniques is developed and simplified so that it is easily useable and 
understandable in order to enable optimal decision-making at an operational level with low complexity and high value.

\section{METHODOLOGY APPLICATION AND VALIDATION}

\subsection{Case study background}

Amplats is a subsidiary of Anglo American PLC, the British multinational mining company. They are the world's leading platinum producer, accounting for around 40 per cent of the global platinum supply. One of the Amplats plants was used to assess and validate the research of this study. During a visit to the selected plant, the motivation and need for this study were established. There it was found that the use of numerical decision-making tools is rather limited in practice, confirming the findings in the literature.

\subsubsection{Critical asset identification}

The method selected for this is TAHPP. It ultimately creates a priority hierarchy of assets according to relevant criteria. Due to the simplicity factor in the development of this methodology, the critical asset analysis is formulated in a manner that requires minimal input. The following data is required for each asset in order to apply TAHPP:

- the current mean time between failures (MTBF) of the asset,

- the current mean time to repair (MTTR) of the asset,

- the time since the last event, and

- $\quad$ the average maintenance cost of the asset.

The MTBF, MTTR, and average maintenance costs are calculated from past failure data. The last event time is simply the time that has elapsed since the last maintenance or repair was done on the asset. The criteria used for the identification are of two kinds: the consequence of a failure occurrence, and the probability that a failure will occur.

1. The consequence of failure occurrence has three elements:

- maintenance cost,

- $\quad$ safety impact, and

- production impact.

2. The probability of occurrence only has two elements:

- $\quad$ MTBF, and

- last event.

The area selected for the case study had eight assets that were included in this analysis. The TAHPP structure for these assets is presented in Figure 4.

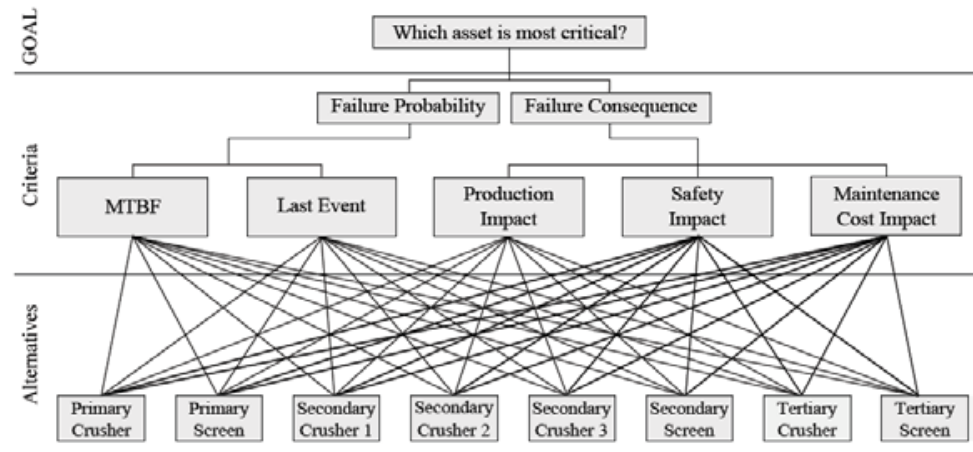

Figure 4: Case study TAHPP structure 
As a result of the pairwise comparison, the extended TAHPP structure in Figure 5 shows the priority values for each asset per criterion.

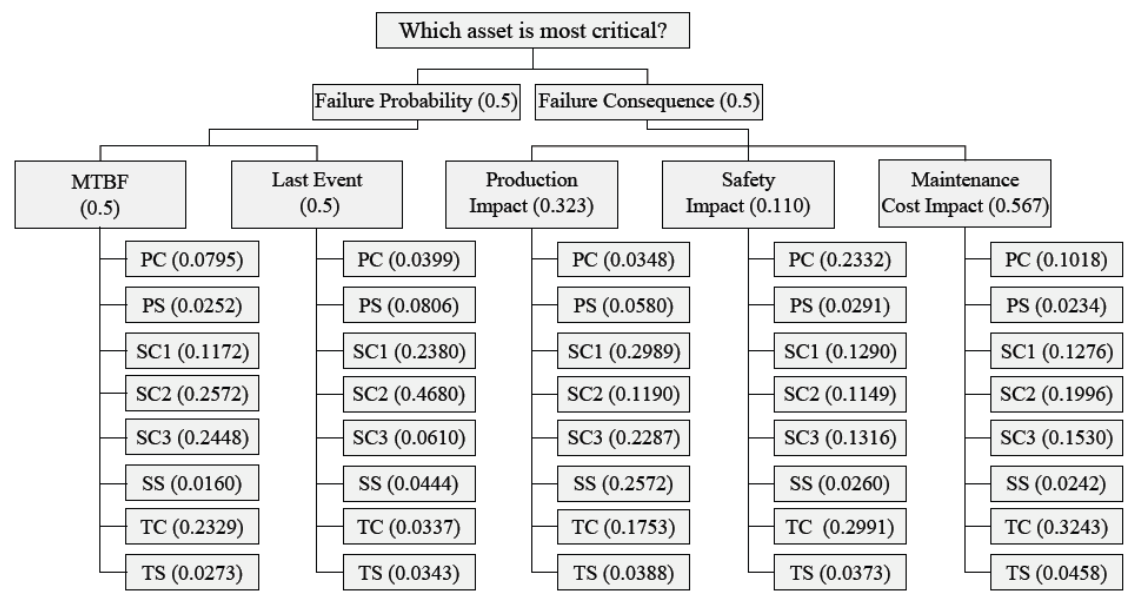

Figure 5: Case study extended TAHPP structure

From these values, the failure probability and failure consequence weights are calculated for each asset. This is illustrated in Figure 6 below.

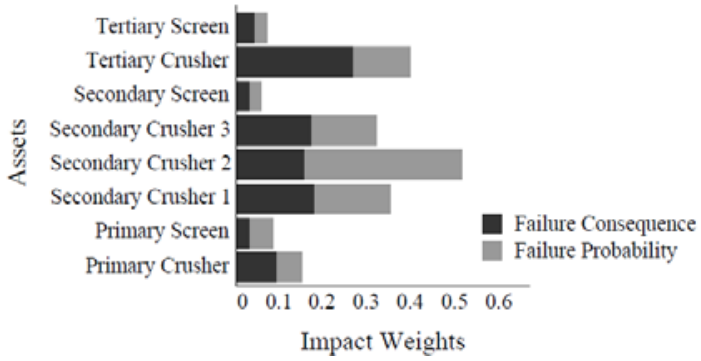

Figure 6: Final consequence and probability weights per asset

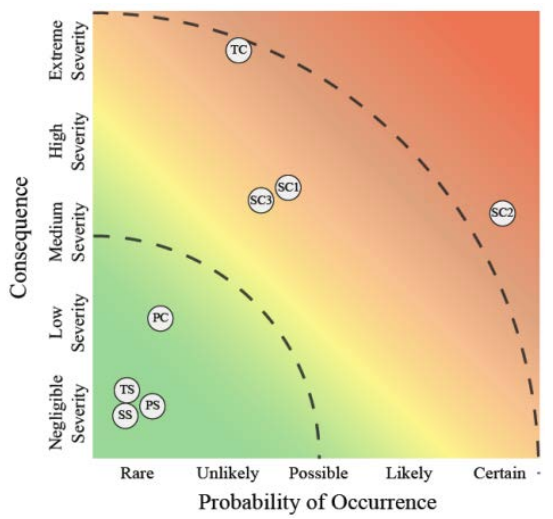

Figure 7: TAHPP criticality grid for visual asset prioritisation

These weights are used to plot the assets on the TAHPP criticality grid, shown in Figure 7. The final criticality values are calculated with a further matrix multiplication, and are shown in Table 2.Table 2: Assets' numerical TAHPP criticality and priority. 


\begin{tabular}{lll}
\hline \hline Asset & Criticality & Priority \\
\hline Secondary Crusher 2 & 0.2635 & A \\
Tertiary Crusher & 0.2034 & B \\
Secondary Crusher 1 & 0.1804 & B \\
Secondary Crusher 3 & 0.1640 & B \\
Primary Crusher & 0.0772 & C \\
Primary Screen & 0.0440 & C \\
Tertiary Screen & 0.0367 & C \\
Secondary Screen & 0.0309 & C \\
\hline \hline
\end{tabular}

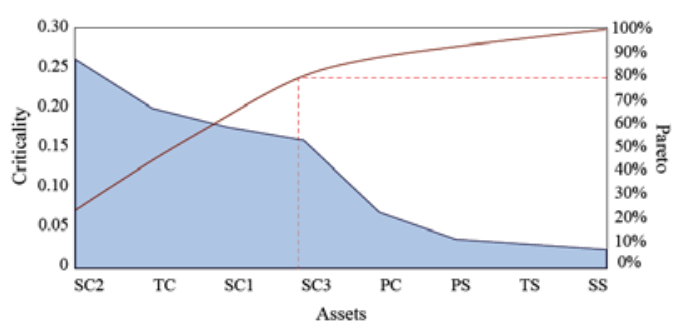

Figure 8: TAHPP Pareto graph

According to this prioritisation, Secondary Crusher 2 is the only asset in the plant with an Apriority. For this reason, the SMART failure mode prioritisation will be applied on the failure modes of Secondary Crusher 2.

A Pareto analysis is done on the TAHPP results to determine the urgency of the actions that are required to reduce the criticality. The Pareto graph in Figure 8 shows that 80 per cent of the criticality is due to four of the eight assets. Evidently 50 per cent of the assets are considered critical, which means that these different assets need to be treated to reduce the critical majority. This indicates that the urgency of the actions is rather high, and needs to be implemented as soon as possible.

A SMART prioritisation is done on the failure modes of Secondary Crusher 2, ultimately to select the most appropriate maintenance tactic for each failure mode.

\subsubsection{Failure mode prioritisation}

For this analysis, the same criteria and the weights used in TAHPP are used. However, quantitative values are generated for the criteria description of each failure mode. The input data required is also similar to the input data of the Identify phase. This data is used to derive the quantitative criteria descriptions.

From the data collected during the case study, it was found that Secondary Crusher 2 has 20 different failure modes. These failure modes were analysed in order to get the necessary inputs for the SMART prioritisation. The visual prioritisation for the failure modes is shown in Figure 9.

A Pareto analysis is done on the priority values of the failure modes to get an estimated urgency; see Figure 10. As shown in the graph, 70 per cent of the failure modes are responsible for 80 per cent of the priority. This is due to the fact that the majority of failure modes are likely to fail, even though they do not have severe consequences. This result shows that maintenance on these failure modes is urgent. 


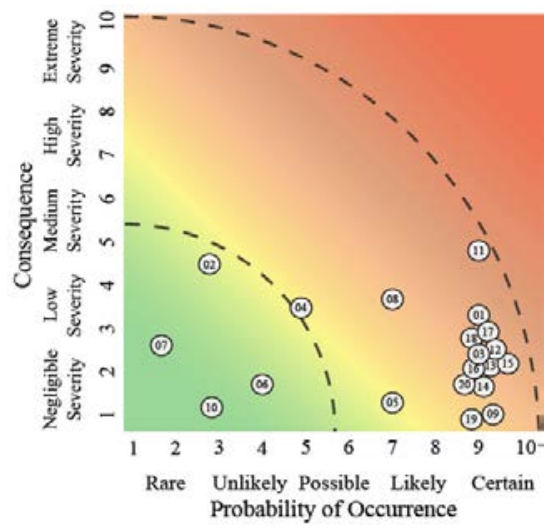

Figure 9: SMART priority grid

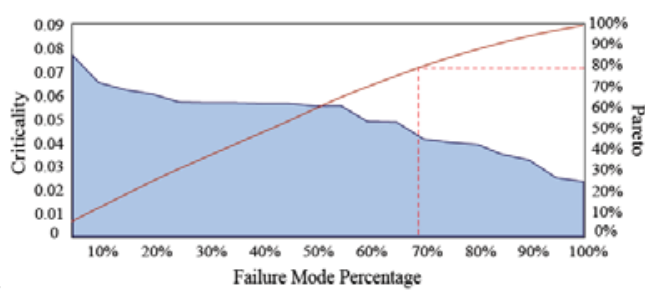

Figure 10: SMART Pareto graph

The challenge is to treat all of these possible failure modes before they occur. The next section discusses the maintenance tactic selection that is done using TOPSIS.

\subsubsection{Maintenance tactic selection}

This is done in order of preference obtained with SMART. Four different maintenance tactics are considered:

- $\quad$ Corrective maintenance

- $\quad$ Preventive maintenance

- $\quad$ Predictive maintenance

- $\quad$ Design-out maintenance

Certain tactics are better for certain failure modes; therefore the following criteria are used to analyse the applicability of these tactics:

- Damage to asset or asset condition after maintenance,

- Production loss or time to maintain, and

- Maintenance-related costs.

The aim is thus to minimise each of these with the execution of the selected maintenance tactic. The maintenance tactics are rated individually on a scale from one to ten for each criterion, corresponding to each failure mode.

In the previous section, with the Pareto analysis, it was shown that the urgency of the actions is high. This is because 70 per cent of the failure modes need to be addressed in order to eliminate 80 per cent of the priority unwanted events. This means that the first 13 modes need to be addressed as soon as possible. The best maintenance tactic for these failure modes is shown in Table 3. 
The maintenance tactics for these 13 failures include seven preventive actions, three corrective actions, two predictive actions, and one design-out action. The remaining failure modes that need to be treated include three corrective actions, three preventive actions, and one design-out action.

Table 3: TOPSIS maintenance strategy selection results

\begin{tabular}{lrl}
\hline \hline & Failure Mode & $\begin{array}{l}\text { Selected } \\
\text { Maintenance } \\
\text { Tactic }\end{array}$ \\
\hline FM11 & High pressure before filters & Preventive \\
FM01 & Choked & Corrective \\
FM18 & Unhealthy flow switch & Preventive \\
FM08 & Thermal Overload & Design-out \\
FM03 & Hydroset fault & Predictive \\
FM12 & Leaking grease pipe & Predictive \\
FM13 & Low oil pressure before filter & Preventive \\
FM14 & Low oil temperature & Preventive \\
FM16 & Oil flow low & Preventive \\
FM17 & Oil pipe leak & Predictive \\
FM19 & Blocked chute & Corrective \\
FM15 & Lube pump tripped & Corrective \\
FM04 & Low spider bearing temperature & Preventive \\
FM02 & High spider bearing temperature & Preventive \\
FM20 & Comms failure & Design-out \\
FM05 & Tighten bolts on top shell & Corrective \\
FM09 & Tripped & Corrective \\
FM06 & Unhealthy speed switch & Preventive \\
FM07 & Crusher overload & Corrective \\
FM10 & High oil temperature & Preventive \\
\hline \hline & & \\
\hline \hline
\end{tabular}

It is clear that preventive maintenance is the preferred maintenance for the majority of the failure modes, and that predictive and design-out maintenance are in the minority. These two maintenance tactics are usually more expensive, which is one reason why they are disliked. Preventive maintenance provides the capability to treat a possible failure mode before the occurrence, and thus can result in increased production and less downtime for maintenance and rectification.

\section{DISCUSSION AND VALIDATION}

The type of decision-making that requires support by this methodology is of an informal nature, and is thus done regularly or periodically. For this reason, the results obtained from this case study are only valid for the time period of the data collection.

The application of this methodology requires someone who is familiar with the system and has experience with its operations. A senior maintenance planner therefore participated in the application during the case study.

The maintenance planner stated that the methodology interface was easy to understand and use. The application was completed without struggle and within a reasonable time period. According to the maintenance planner, anyone with the necessary knowledge of the plant and its operations would be able to use this methodology without effort. All of this confirms that the methodology development adheres to its simplifying purpose.

With the interpretation of the results, it was stated that the implementation of this methodology would have practical value. The maintenance planner was satisfied with the results, and said that this is an effective tool that can be used in planning maintenance activities 
Having effective and accurate maintenance management contributes to a large extent to the success of PAM. With the focus on numerical decision-making tools, it was identified that there is a tendency in practice not to use the techniques because of the great degree of complexity and the effort required. Influential decisions about maintenance management on an operational level were identified in order to find the most appropriate numerical techniques that can support the management of maintenance effectively and efficiently. The most applicable techniques were identified to create a simplified numerical decision-making methodology. The purpose of this methodology is to make effective maintenance decisions on an operational level by selecting the most appropriate maintenance tactics for different failure modes of a system or asset.

The applicability of the developed methodology was investigated theoretically to validate its applicability to an actual situation. Using a case study, the methodology was applied to an actual scenario to validate the practical value of the methodology.

Amplats provided the opportunity to apply the simplified numerical decision-making methodology in a real-world situation. Evidently the application was easy, understandable, quick, and effortless, and was referred to as a valuable tool in planning maintenance actions. This result indicates that such a tool can ease the management of maintenance decisions on an operational level, and can lead to decreased failure occurrences and down times.

\section{REFERENCES}

[1] Amadi-Echendu, J. 2004. Managing physical assets is a paradigm shift from maintenance. IEEE Transactions on Engineering Managment, p. 1156-1160.

[2] Schnettler, A., Schneider, J., Neumann, C., Hografer, J., Wellbow, W. \& Schwan, M. 2006 Asset management techniques. Electrical Power and Energy Systems.

[3] Mitchell, J. 2002. Physical asset management handbook, Clarion Technical Publishers.

[4] Hastings, N. 2010. Physical asset management, Springer.

[5] Tywoniak, S., Rosqvist, T., Mardiasmo, D. \& Kivits, R. 2008. Towards an integrated perspective on fleet asset management: Engineering and governance considerations. in Proceedings of the 3rd World Congress on Engineering Asset Management and Intelligent Maintenance Systems.

[6] Mitchell, J. 2007. Physical asset management handbook, Clarion

[7] Myburg, J. 2007. Physical asset management system concepts.

[8] Mobley, R. 2002. An introduction to predictive maintenance. Butterworth-Heineman

[9] Ben-Daya, M., Duffuaa, S., Raouf, A., Knezevic, J. \& Ait-Kadi, D. (eds). 2009. Handbook of maintenance management and engineering, Springer.

[10] Al-Tarawneh, H.A. 2012. The main factors beyond decision-making. Journal of Management Research, 4

[11] Rue, L. \& Bayrs, L. 1986. Management theory and application, 4th ed., Irwin Homewood: IL.

[12] Saaty, T. 1990. How to make a decision: The analytic hierarchy process. European journal of Operational Research, 48(1), pp. 9-26.

[13] Bushan, N. \& Rai, K. 2004. Strategic decision-making: Applying the analytical hierarchy process. Springer.

[14] Fülöp, J. 2005. Introduction to decision-making methods. BDEl-3 Workshop, Washington.

[15] Laininen, P. \& Hämäläinen, R.P. 2002. Analysing AHP-matrices by regression

[16] Escobar, M., Aguaròn, J. \& Moreno-J imènez, J. 2004. A note on AHP group consistency for the row geometric mean priorization procedure. European J ournal of Operational Research, 153(2), pp. 318-322.

[17] Starfield, T. 2005. Simple Multi-Attribute Rating Technique (SMART)

[18] Barron, F.H. \& Barret, B.E. 1996. The efficacy of SMARTER - Simple multi-attribute rating technique extended to ranking, Actaa Psychologica, 93, pp. 23-36.

[19] Sachdeva, A., Kumar, D. \& Kumar, P. 2009. Multi-factor failure mode criticality analysis using TOPSIS. J ournal of Industrial Engineering International, 5(8), pp. 1-9.

[20] Olson, D. 2004. Comparison of weights in TOPSIS models. Mathematical and Computer Modelling.

[21] Marović, Z. 2010. Modification of TOPSIS method for solving of muli-criteria tasks. Yugoslav J ournal of Operations Research, 20(1), pp. 117-143. 